
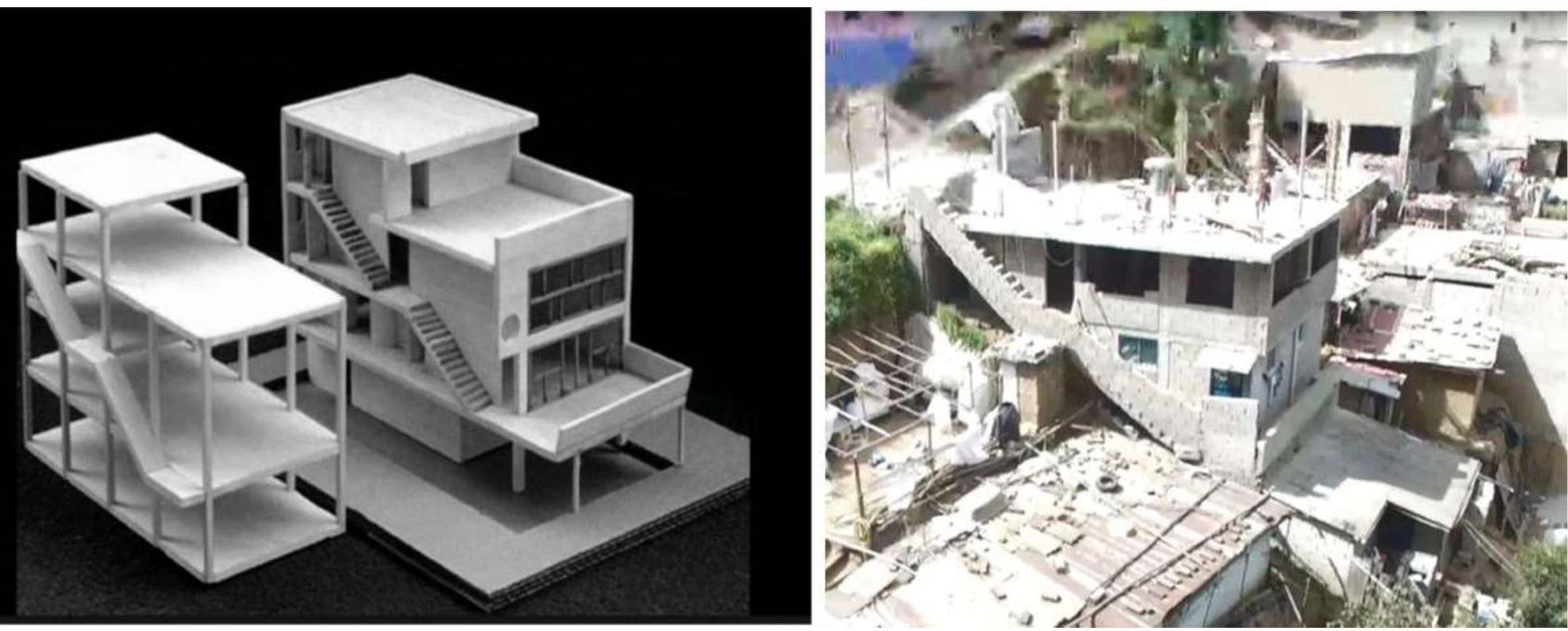

Figura 1. Abstracción versus intuición: Izquierda Escalera Villa Citrohan 1922; Derecha Escalera lineal en vivienda familia Singo. Fuente: https://www.youtube.com/watch?v=NuBPcZmUN-w y del autor 2017 respectivamente.

\title{
Tiempos de habitar.
}

\section{La escalera como mecanismo de transformación y configuración de la vivienda}

Tempos de Habitar.

A escada como mecanismo de transformação e configuração das habitações

Times for inhabiting.

The staircase as a mechanism for transforming and configuring dwellings

Maria Belén Granja-Bastidas

Estudiante de Doctorado en la Universidad Politécnica de Madrid, Madrid, España

maria.belen.granja.bastidas@gmail.com | https://orcid.org/0000-0001-5953-4734 


\section{Resumen}

El artículo nos muestra el contraste existente entre los mecanismos proyectuales para la definición del recorrido y circulación desde la disciplina arquitectónica, en general, y los desarrollados desde la experiencia de habitar dada en barrios populares de Quito. El estudio se desarrollará en dos partes: la primera es una visión conceptual desde la arquitectura académica a través de algunas obras de Le Corbusier y Fumihiko Maki, de cómo se utiliza el concepto de circulación para la estructuración y organización espacial desde el diseño; y la segunda es una reconstrucción del proceso iterativo de las escaleras y circulaciones en la ciudad autoconstruida aplicada en el barrio de Atucucho. Como conclusión hemos identificado en el hábitat popular 10 (diez) modelos de habitar estructurados a partir de la escalera como nociones topológicas en el que la escalinata es un instrumento que permite la transformación en el espacio y su configuración posibilita que la casa se modifique y se adapte a la topografía y ofreciendo así nuevas dinámicas del habitar.

\section{Resumo}

0 artigo nos mostra o contraste existente entre os mecanismo projetuais para as definições de promenade e circulação na arquitetura, em geral, e os desenvolvimentos das experiências de habitar ocorrida em bairros populares de Quito. 0 estudo se desenvolve em duas partes: a primeira é uma visão conceitual da arquitetura acadêmica através de obras de Le Corbusier e Fumihiko Maki, e como se utilizam os conceitos de circulação para a estruturação e organização espacial do desenho; e a segunda parte é uma reconstrução do processo interativo das escadas e circulações na cidade autoconstruída existente no bairro de Atucucho. Como conclusão identificou-se dentre as habitações populares dez modelos de habitar estruturados a partir das escadas como noção topológica em que a mesma é um instrumento que permite a transformação no espaço e sua configuração possibilita que a habitação se modifique e se adapte a topografia, oferecendo assim novas dinâmicas para o habitar.

\begin{abstract}
The article contrasts the design mechanisms for defining routes and circulation from the point of view of the architecture discipline in general, with the mechanisms developed from the experience of living in Quito's workingclass neighborhoods.
\end{abstract} The text consists of two parts: the first, based on academic architecture, is a conceptual view of a number of works by Le Corbusier and Fumihiko Maki - how the concept of circulation is used for structuring and spatial organization from a design standpoint; and the second is a reconstruction of the iterative process of staircases and circulation in self-constructed cities, as applied to the Atucucho neighborhood in Quito. In conclusion, 10 models of living structured around the staircase were identified in a low-income habitat. In these topological notions the staircase is an instrument that enables transformation in the space and its configuration makes it possible for houses to be modified and adapted to the topography, thus offering new living dynamics.

\section{Palabras claves}

$\begin{aligned} & \text { Escaleras, circulaciones } \\ & \text { verticales, } \\ & \text { populares, Quitondas }\end{aligned}$

\section{Palavras chaves}

Escadas, circulações vertivais, habitações populares, Quito

\section{Keywords}

Stairs, circulation, selfconstruction, promenade, popular housing. 
L Architecture arabe nous donne un enseignement précieux. Elle s'apprécie a la marche, avec le pied; c'est en marchant, en se déplacant que lon voit se développer les ordonnances de larchitecture. C'est un príncipe contraire a farchitecture baroque qui est concue sur le papier, autour d'un point fixe théorique. Je préfere lenseignement de /architecture arabe."

1 | Le Corbusier, 1984, p.24.

2 | La concepción de tiempo como memoria es tomado de las categorias con que define (Tomillo Castillo, 2016).

El estudio de Atucucho se desarrolla a profundidad en (Granja B., 2019) tesis doctoral del autor en desarrollo,

\section{Introducción}

En el texto que antecede se constata cómo Le Corbusier intuye una diferenciación esencial entre la concepción dinámica que estructura los recorridos de la ciudad árabe y a la ciudad barroca, que se concibe desde el plano. La diferencia radica en que en la ciudad tradicional la calle se configura paulatinamente como consecuencia de la superposición de actividades recurrentes; la circulación, más que esquemas lineales de relación, constituye elementos espaciales "con una dimensión poliédrica" (Monteys, 2017, p. 8) que reúnen además una noción de tiempo acumulativo como registro o memoria ${ }^{2}$ de las interrelaciones y acciones que suceden en el espacio.

Partiendo de esta concepción ambivalente sobre el recorrido (Figura 1), la presente investigación contrasta las nociones sobre circulación desde, por lo menos, dos enfoques. En primer lugar, desde la disciplina arquitectónica académica, que entiende al recorrido como un esquema relacional que estructura el espacio desde el movimiento y el objeto arquitectónico se concibe como estático y desde el cual, casa y ciudad son un escenario previo en el que se desarrolla la vida. $Y$, en segundo, desde los mecanismos de la ciudad espontánea no planificada, en que la arquitectura se define a través del cambio y la transformación: "la casa y la ciudad adquieren una connotación vital” (Tomillo, 2016, p. 37) susceptibles de transformarse y reconfigurarse paulatinamente de forma fenomenológica e incorporando en el recorrido interior las rutinas cotidianas y cambios cíclicos que experimentan tanto las personas al habitar desde el interior, como los elementos externos del contexto natural en las que el propio edificio y la ciudad envejecen y se deterioran.

Adaptado al estudio a la ciudad latinoamericana, el contraste de estas perspectivas se materializa en las diferencias entre la ciudad planificada formal y la autoconstruida informal. Para relacionar ambos ámbitos, la investigación se desarrolla en dos partes: la primera es un análisis conceptual del recorrido en la arquitectura formal identificado en obras de Le Corbusier y Maki, y la segunda es un estudio de caso, en el cual la reconstrucción del proceso iterativo de las escaleras y la circulación en la ciudad autoconstruida se aplica al barrio Atucucho ${ }^{3}$.

El estudio documental se realiza desde posiciones teóricas como la del CIAM, representado en obras de Le Corbusier; muestra seleccionada aquí por la fuerte incidencia de su pensamiento en Latinoamérica, difundido tanto desde las conferencias dictadas en sus viajes entre 1929-1959 (Henríquez, 1956; López Guzmán, 2003; O’Byrne Orozco y Daza, 2018), como en la ideación de los planes que desarrollo urbano de Bogotá y Brasilia (Bullaro, 2014; O’Byrne, 2018) y en la formación de veinte y dos arquitectos colaboradores, cuya labor fue una de las principales fuentes de difusión de la arquitectura moderna en la región (Quintana Guerrero, 2014). La otra postura define los procesos de la ciudad autoconstruida, en relación con Fumihiko Maki y su "teoria de la forma agrupada", concebida 


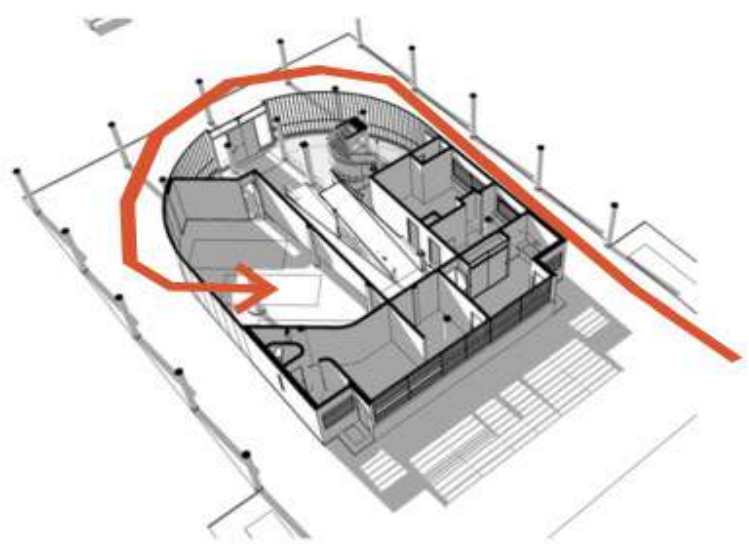

1ER. PASEO

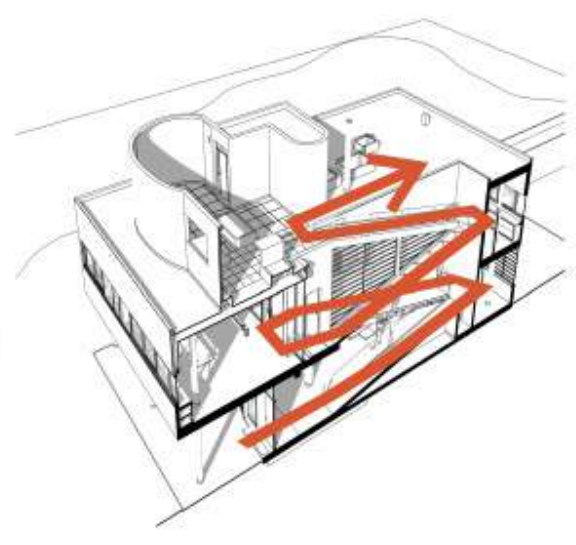

2DO. PASEO

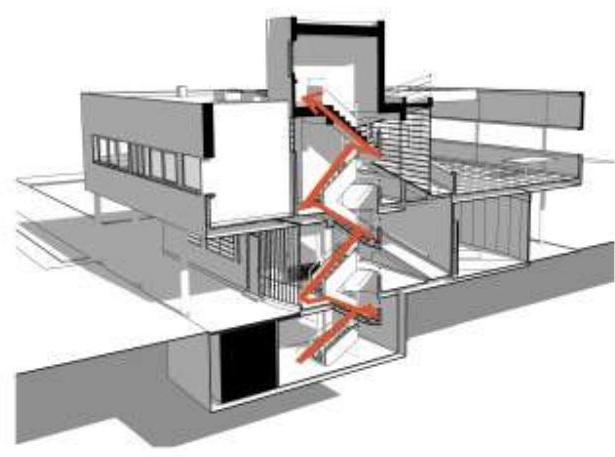

3ER. PASEO

Figura 2. Los 3 tiempos de habitar desde el recorrido en Villa Saboye. Fuente: Elaboración de la autora en base a grafico de Aramis Quicaño-Bibliocad.

como propuesta alternativa a los modelos urbanos y a la arquitectura seriada del CIAM, y la que, pese a su filiación con el metabolismo, es opuesta al manejo de megaformas (Garcia y Muñoz, 2014). Si bien Maki no tiene mayor incidencia conceptual en Sudamérica, fue escogido para este estudio porque los procesos de la vivienda informal autoconfigurados en el lugar, iterativamente en el tiempo, y en relación directa y paralela al barrio al que pertenece, coinciden con lo que Maki realiza en Hillside Terrace, que Koolhaas, descrito en Qiu (2013), denomina "urbanismo de crecimiento lento"

De esta manera, tanto del análisis teórico como el estudio de caso permitirán desarrollar el objetivo central de la investigación que consiste en identificar las invariantes arquitectónicas desde el recorrido en la ciudad informal como un aprendizaje de los mecanismos vitales de transformación de las ciudades autoconstruidas, buscando respuesta a la misma pregunta de Maki (1964): ¿es posible crear formas agrupadas significativas desde el diseño? (p. 20). A través de la identificación de estos mecanismos se espera contribuir al desarrollo de modelos alternativos de vivienda social.

\section{Metodología}

Se emplea como metodología el contraste entre los mecanismos proyectuales para la definición del recorrido y la circulación desde la disciplina arquitectónica académica, por una parte, y los desarrollados desde la experiencia de habitar en barrios populares 

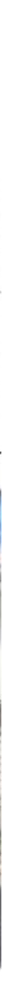

Figura 3. Grados de Desarrollo identificados en la conformación de una Calle-escalinata Atucucho. Fuente: Dibujos de Luis Ortega y fotografias de la autora (2017).

de Quito, por otra. El trabajo se organiza en dos apartados. El primero es un análisis documental del concepto de "recorrido" en obras de arquitectura desde las propuestas de Le Corbusier y el concepto de "promenade" en las casas Citrohan, La Roche y Saboya, como también de la propuesta respecto a las "secuencias" de Fumihiko Maki, según los mecanismos usados en Hillside Terrace (Qiu, 2013; Fernández, Ollero y Mozas, 2013).

El segundo apartado es un estudio de caso, en el Barrio Informal Atucucho, Quito-Ecuador, llevado a cabo mediante el análisis de un muestrario de cien 100 casas, efectuado recorriendo cada vivienda, en compañía de su dueño, quien narra el proceso de construcción de la casa mientras se la transita, lo cual permite recrear las "secuencias" de crecimiento y las lógicas de organización internas del domicilio y el barrio. A este procedimiento se le denominó "Censo háptico". La comprensión a escala urbana de las interrelaciones barriales utiliza las herramientas operativas de Maki (1964).

\section{Parte 1:}

Los tiempos de habitar, desde el diseño arquitectonico De acuerdo a Reyes (2014), la concepción espacial desde el ámbito académico en el siglo XX se explica desde dos momentos y posiciones teóricas: en primer término, la visión mecanicista de inicios de siglo, con los que se estructuran los principio del CIAM, que en arquitectura se caracteriza por las intervenciones higienistas, funcionalistas y por la introducción del concepto de fabricación en 

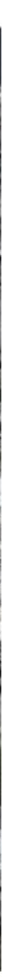

Figura 4. Secuencias de Recorrido interno hasta la zona central del barrio. Fuente: Autora.

serie. A nivel urbano, se redefinen las escalas de relación adaptadas a las nuevas condiciones de movilidad y velocidad condicionadas por el vehículo. El siguiente enfoque surge de la postguerra, como crítica y alternativa a la anterior, con los movimientos del postmodernismo y el TEAM 104 intentando reconciliar la arquitectura con el habitante, el cambio y la contingencia, retomando el análisis de las ciudades tradicionales y sus mecanismos de interacción colectiva, crecimiento y variación, y, fundamentalmente, buscando recuperar la relación con el concepto de calle tradicional.

\section{Enfoque teorico del CIAM; La vivificación de la Promenade interior y} la muerte de la calle

El concepto de "promenade" de Le Corbusier constituye un mecanismo de gran importancia en la configuración de algunas de sus obras, mediante el cual confiere un valor adicional al tema solo relacional del recorrido que es el paseo escénico (Benton, 1987). Mas el desarrollo de este concepto, según Monteys y Fuertes (2016), es cíclico y evolutivo, como se pone de manifiesto a continuación.

Si se analiza el recorrido de la Casa Citrohan (1920), se advierte su carácter principalmente funcional, como articulador del espacio (Figura 1). Resaltan, como cualidades de la vivienda, su condición de sencillez en que la escalera se convierte en columna vertebral de la vivienda. En efecto, el pensamiento del Le Corbusier en esta época buscaba el desarrollo de sistemas de vivienda de fácil replicación (O’Byrne Orozco y Daza, 2018).
4 Los origenes del TEAM se analizan en profundidad en (Juárez Chicote y Rodríguez Ramirez, 2014] 


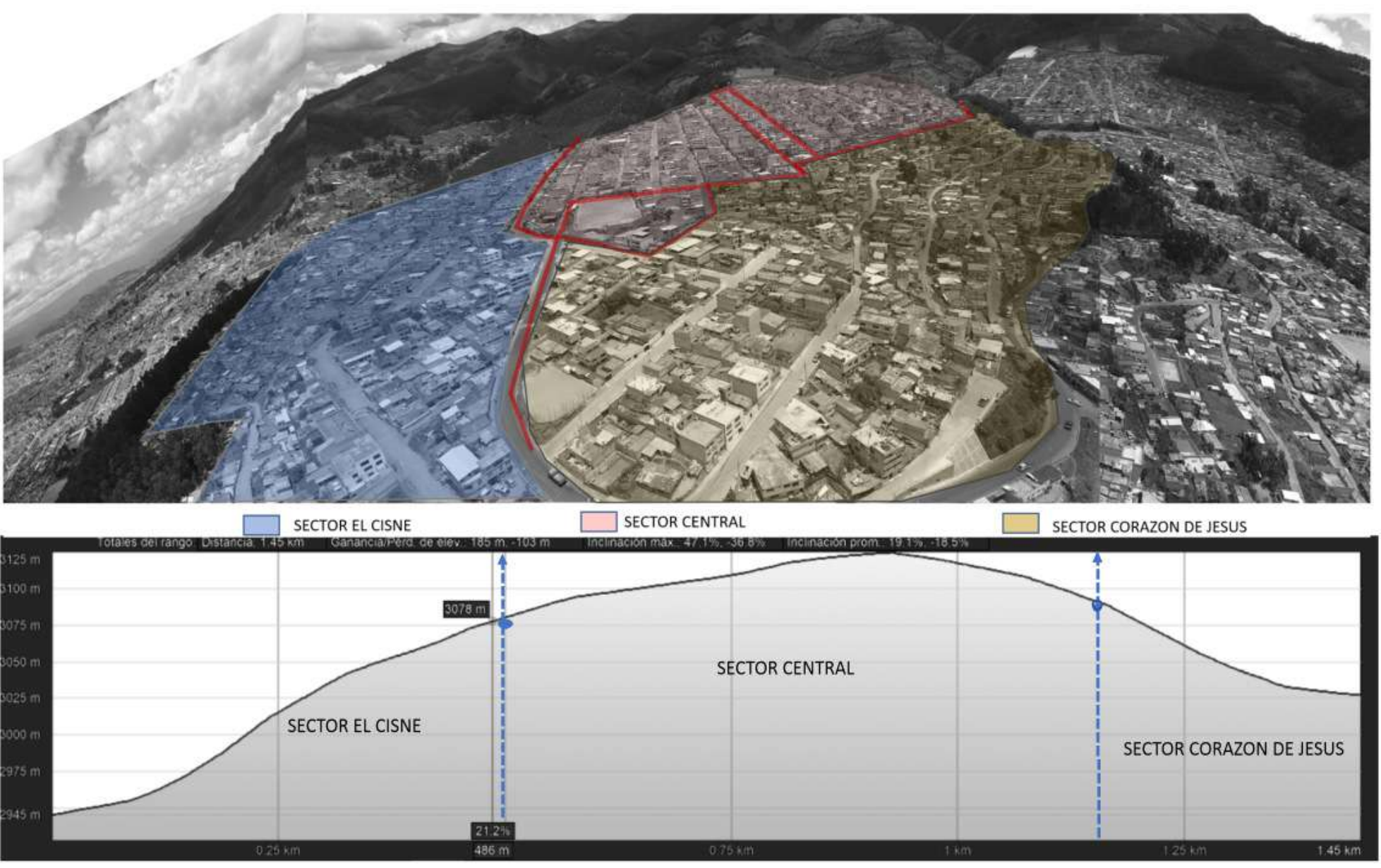

Figura 5. Conformación de zonas del barrio adaptado a la pendiente y secuencias viales principales. Fuente: Elaboración de la autora en base a mapeo en Google Earth.

Es notorio el cambio conceptual respecto al recorrido en la Villa La Roche (1923-1925), en que Le Corbusier introduce ya el concepto de promenade (Benton, 1987), el particular emplazamiento de la villa condiciona de partida un recorrido exterior monumental que se traslada al interior de la casa, donde adquiere un carácter de paseo escénico mediante la rampa, en el que se percibe detalladamente el juego espacial propuesto (Gonzales Cubero, 1991). Al compararla con La Villa Citrohan, se nota cómo La Roche se contrapone con los aspectos funcionales del recorrido en las acciones cotidianas. El punto primordial es que el habitar está cargado también de acciones menos poéticas y no por ello banales sino necesarias, pues las circulaciones en la vivienda deben ser entonces ambas cosas, permitiendo el desarrollo práctico de actividades cotidianas en los que prima la fluidez del recorrido y, asimismo, actividades en que se transita pausadamente por una rampa.

Para el desarrollo de la Saboye, en 1929, se observa cómo además a nivel urbano se plasma la idea de calle con un nuevo rol condicionado por el vehículo, en que para Le Corbusier no tiene cabida ya la reducida calle tradicional a las que denomina "rue corridor", por lo que propone vías abiertas rodeados de áreas verdes que permitan disfrutar de la velocidad (Monteys y Fuertes, 2016). De esta manera, en la Saboye el recorrido se inicia desde el automóvil; gesto con el cual Le Corbusier introduce tres nociones temporales en la villa: el tiempo cíclico y la noción de velocidad, que se evidencia en este recorrido exterior envolvente en torno a la Saboya; el tiempo práctico de las 



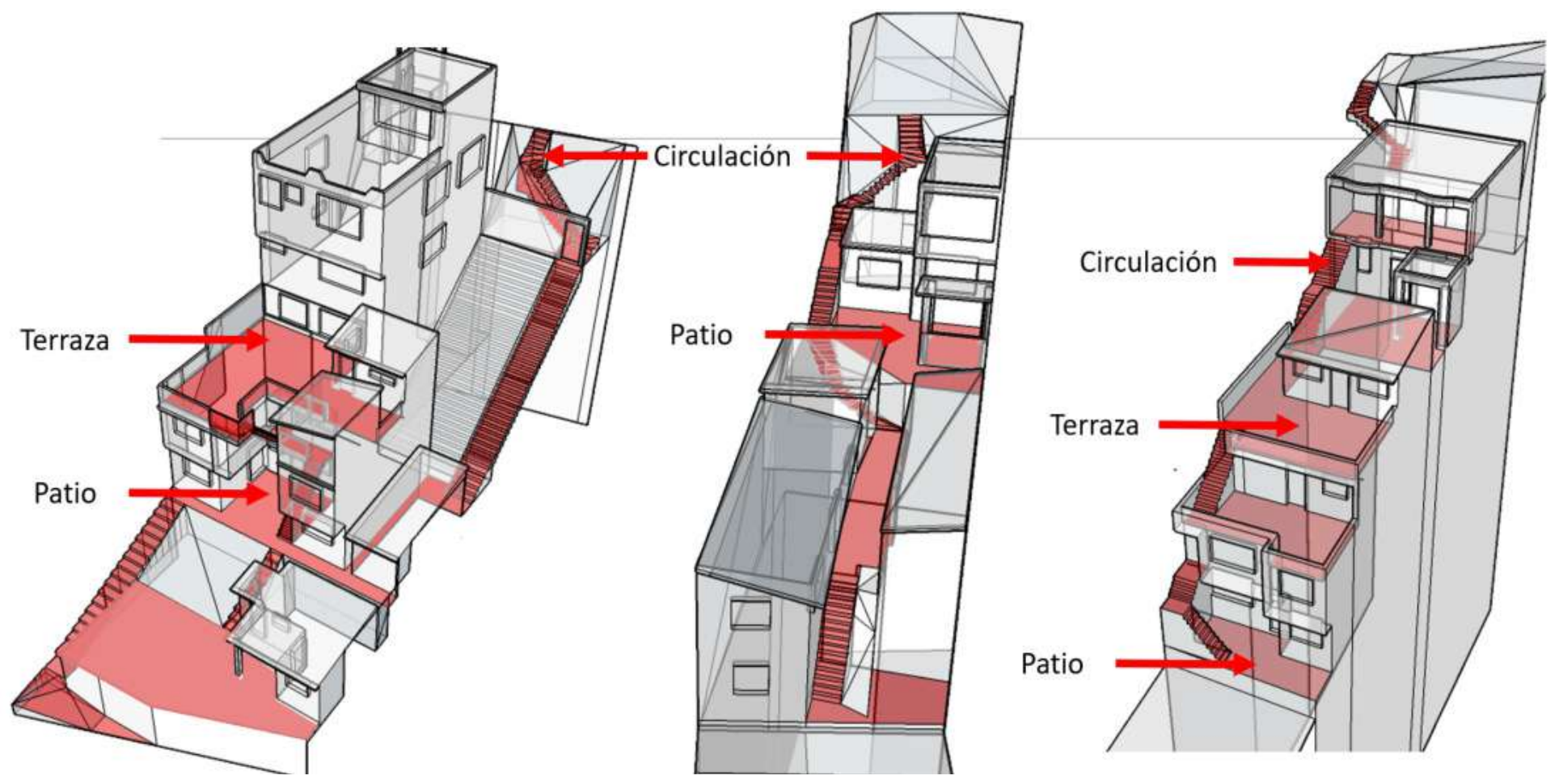

Figura 7. Identificación de Invariancias. Fuente: Santiago Ibujes para Taller UCE- FAU (2018).

de asociación de la ciudad tradicional en la que, además del desarrollo de la vivienda como edificio, está implícito el desarrollo colectivo de la ciudad a través de las secuencias y relaciones de los espacios de conexión a la arquitectura, como la calle y la plaza. De esta manera, las secuencias que explica Maki desarrollan tanto la noción del tiempo colectivo como el tiempo de habitar. Su propuesta, en definitiva, determina condiciones para crear formas agrupadas donde el diseño no sea netamente una conjetura, sino una respuesta concreta específica a los eventos, condiciones y necesidades de sus habitantes.

Maki logra aplicar muchas de estas ideas en Hillside Terrace (Fernández et al., 2013) a través del mecanismo en que el arquitecto interviene paralelamente en los procesos de la ciudad de forma cotidiana, por medio de un proceso de diseño permanente. durante más de 40 años. Cambia, de esta manera, el concepto de diseño entendido como un acto inicial, a un concepto de proyecto comprendido como un acto permanente que va de la mano con la duración de los eventos y sucesos de la ciudad. A diferencia de las propuestas de Le Corbusier, el trabajo de Maki se caracteriza por la concepción de la arquitectura no como un elemento singular sino como parte de una "forma agrupada".

En las secuencias y la estructuración de Hillside Terrace (Figura 10) se aprecia la importancia que Maki da, en el conjunto, al desarrollo de la calle, recuperándola como elemento articulador y dando respuesta directa, por medio de gestos formales de la 
arquitectura, al vínculo con la calle a través de la creación de lo que él mismo (1964) define como espacios de mediación que permiten una interrelación intensa y dinámica de la calle: las secuencias peatonales y los edificios en el itinerario urbano cotidiano.

\section{Parte 2:}

\section{Estudios de Caso, el tiempo como cambio y transformación}

\section{Construcción de la ciudad desde el habitar}

A partir de lo que señalan Sáez, García y Roch (2010), el crecimiento en zonas informales se da de manera simultánea: casa, parcela calle y barrio. Pero, coincidiendo con (Rodríguez Ramírez, 2016), son los desplazamientos, las conexiones y la accesibilidad, los elementos que configuran y estructuran el barrio de forma paulatina (Figura 3). Así, por ejemplo, en Atucucho, en el que su emplazamiento se realiza sobre lo que originalmente era una hacienda, se reconoce que el trazado vial de la misma determina el eje primigenio del barrio que posteriormente conformaría la calle Julio y Carlota Jaramillo, hoy eje principal de circulación interna (Granja y Cuenca, 2017). O sea, que el trazado de la calle es el código generativo del barrio (Salingaros, Brain, Duany, Mechaffy y Philibert-Petit, 2006, p. 7) y al ser este paralelo a la topografía hace que el barrio luzca como un manto que recubre la montaña. .

Adicionalmente, las rutinas recurrentes al interior del barrio determinan las jerarquías y usos de las vías internas. Y, a través de los elementos de circulación, se configuran los edificios, se delinean las calles, con la particularidad de que tanto forma como funciones se dan en tres escalas simultáneas que parten de la mediagua a la casa, de la casa a la calle, y de la calle al tejido del barrio. En definitiva, el sistema de configuración surge de la interacción social e individual en el contexto hacia los edificios (Pozueta, Lamíquiz y Porto Schettino, 2009, p. 183).

\section{La escalera y la vida cotidiana}

Tengo operada una rodilla por un problema de los huesos y la otra tengo que operarme, entonces subo con dificultad las gradas. Son 100 gradas... A lo que voy tengo que subir las 100 gradas para irme y a lo que vuelvo vuelta 100 gradas tengo que subir Testimonio de doña Nieves Chango, moradora barrio Atucucho (2017)

El testimonio de doña Nieves pone de manifiesto sus desplazamientos cotidianos al interior del barrio; al hacer una reconstrucción de la secuencia (Figura 4), se constata que, en efecto, son cien los escalones necesarios para llegar de la parada del bus a su casa. Sin embargo, el recorrido de doña Nieves no es el más sencillo para tomar el bus, pues está ligado a la necesidad de relación vecinal, que consigue tomando el bus, cerca del Centro del Barrio, aunque ello implica mayor complejidad. Lo que revela que las razonas prácticas no son el único motivante para recorrer el espacio, como en la promenade de Le Corbusier.

La escalera como espacio relacional

El barrio de Atucucho posee en su interior tres subsectores (Alvarado, 2011), conformados según la topografía. Como ilustra la Figura 5, en base al perfil puede notarse cómo los límites de la zona 

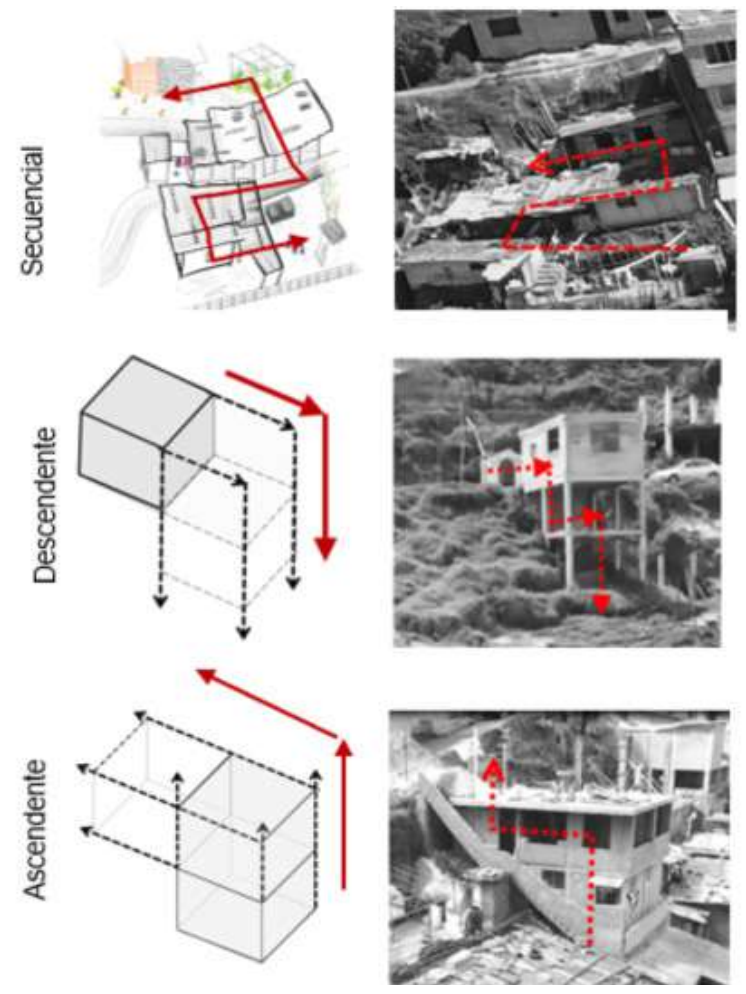
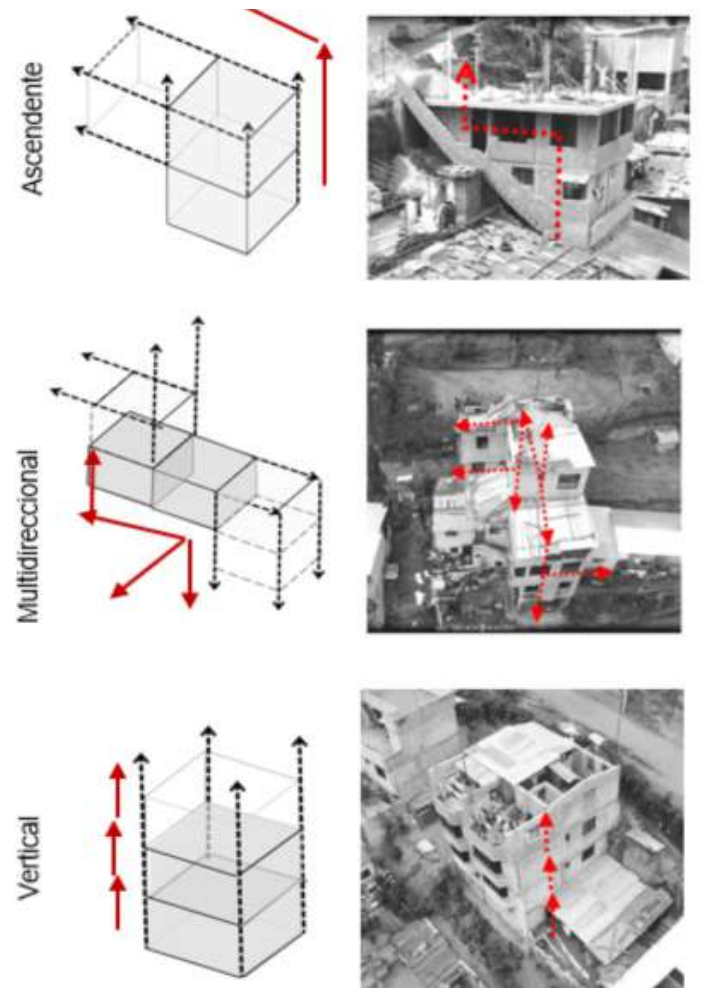

Figura 8. Esquemas de crecimiento secuencial. Fuente: Elaboración de la autora.

central coinciden con el cambio brusco de nivel, que se da hacia los costados, y en ese punto de inflexión inician al costado derecho, Corazón de Jesús y al izquierdo, El Cisne.

En la investigación efectuada, se han identificado dos ejes estructurantes del barrio (Figura 5); en general, y de acuerdo con el estudio en otros barrios de Quito (Granja, 2018) estos ejes están asociados con el sistema principal de transporte público. La jerarquía y tipología de las vías depende de la topografía, de modo que las calles con pendientes mayores a 15 grados se desarrollan con escalinatas comunales.

En su mayoría, las vías de uso vehicular son paralelas al eje principal, en cuya zona central son calles carrozables y, hacia los costados, en las zonas de pendiente mayor, como El Cisne y Corazón de Jesús, estas se convierten en escalinatas comunales.

A través de un análisis del sistema de circulación interno de las viviendas, se puede apreciar como la escalera y las circulaciones de la casa constituyen una columna vertebral articulada en la calle (Monteys, 2017), volviéndose esta, por tanto, el espacio de conexión y organización entre las viviendas (Klaufus, 2009). Tal organización incide incluso en las mingas comunitarias.

Se advierte también cómo la pendiente repercute en el desarrollo de la vereda y en los accesos a las casas (Figura 6): en la zona central, estas se estructuran en forma paralela, y en los costados más empinados, las diferencias de nivel entre calle y casa se resuelven a través del porche que constituye un punto crucial de 


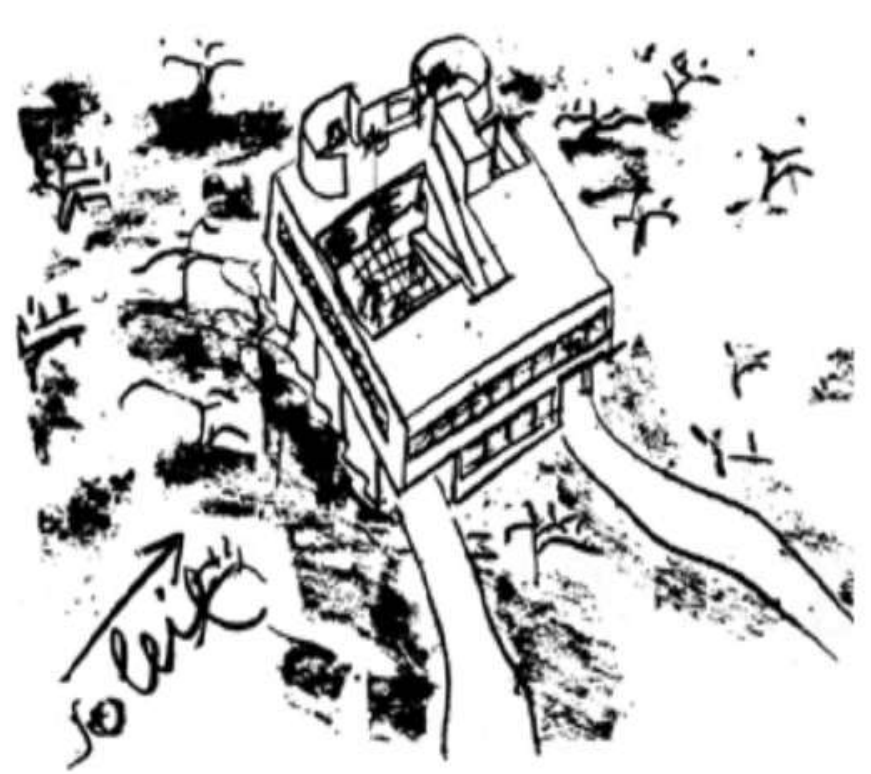

A) RELACION CASA CIUDAD- VILLA SABOYA

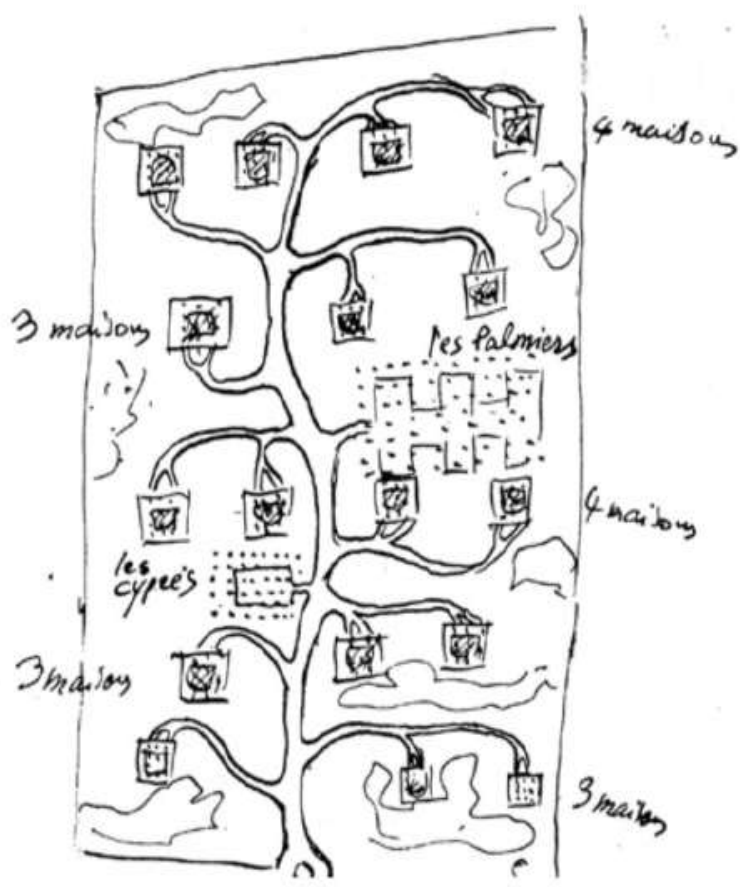

Figura 10. Comparación relación Casa-ciudad en Villa Saboye, Hillside Terrace y Barrio Autoconstruido AtucuchoQuito Ecuador. Fuente: Villa Saboye: Le Corbusier (1999, p.161 ); Hillside Terrace: http://berkeley-2007-branner. blogspot.com/2007_02_01_archive.html; y Barrio Atucucho elaborada por Valeria Rivero para Taller UCE FAU (2018).

para la crianza de animales, y se ha modificado la circulación en la parte posterior, para vincularse con el terreno de la hija.

Una familia de 6 (seis) personas (Figura 11 derecha) inicia su construcción en el bloque inferior; con el pasar del tiempo los hijos crecen y forman nuevas familias, pero los padres del núcleo original se separan. La vivienda debía crecer y además tenía que dividirse; la solución a la que llegan se plasma en una grada externa superior de la casa, que posibilita que la madre viva en el bloque de arriba, con una tienda, el padre habite en el bloque inferior y sus 3 hijos, con sus correspondientes familias, ocupen el resto de la edificación. De esta manera, todos ganan.

Como se ha visto en los ejemplos anteriores, la grada directamente vinculada con la pendiente se convierte en un mecanismo que permite la adaptación a los cambios y al crecimiento, en su proceso de conversión de casa unifamiliar a multifamiliar; $y$, además, define el esquema organizacional, actuando la escalera como una columna vertebral en la configuración de la casa.

La escalera como posibilitador del crecimiento

Siguiendo a Sáez et al. (2010), la casa crece desde un nodo o pixel, circunscrita a su lote, pero dependiendo de dos aspectos: las necesidades socioeconómicas de cada familia y la adaptación topográfica. Así, por ejemplo, aun cuando se trate de casas precarias hechas con materiales efímeros (Figura 8), denominadas por sus dueños como "mediaguas" (Klaufus, 2009), en las que sus habitantes requieren crecer, las soluciones se dan en una planta sobre la superficie 

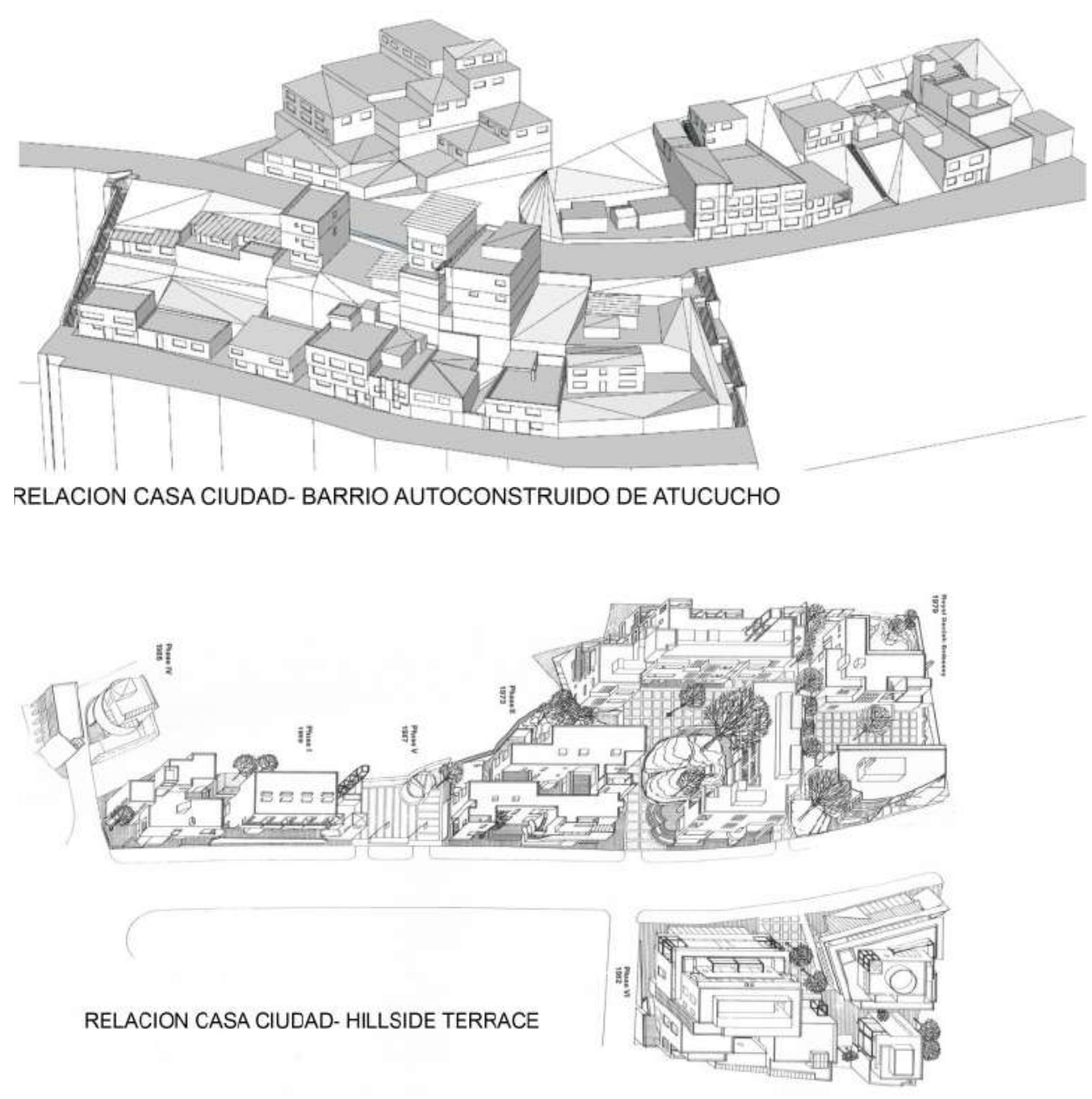

del lote y se distribuyen en secuencias lineales para optimizar la distribución espacial a través del recorrido (Granja y Cuenca, 2017).

En cambio, cuando el crecimiento económico de la familia va en relación directa con el crecimiento de la vivienda, las casas se conciben como "permanentes" y poseen una estructura estable. En este caso (Figura 8), crecen según la ubicación del módulo inicial de la vivienda en la topografía, de modo que:

a) si este se dispone en la parte inferior la vivienda, crece de manera ascendente;

b) si este se dispone en la parte superior, crece de manera descendente;

c) si este se dispone en la parte central, el crecimiento es multidireccional.

En este sentido, existen también:

d) casas que ocasionalmente parten de planos ya definidos y que poseen plantas tipo, en cuyos casos el crecimiento se da de forma vertical.

e) necesidades particulares de cada familia que generan un espacio de relación común como un patio, entonces, la casa crece en torno a este, y se usa como lavandería, huerto o, incluso, talleres de trabajo.

La escalera como elemento de adaptación a la topografía

El barrio posee pendientes de hasta 60 grados, la organización de cada vivienda está supeditada a la pendiente que presenta; por ello la forma de la escalera juega un rol fundamental, es el mecanismo que facilita la adaptación de la vivienda a la topografía. La Figura 9 


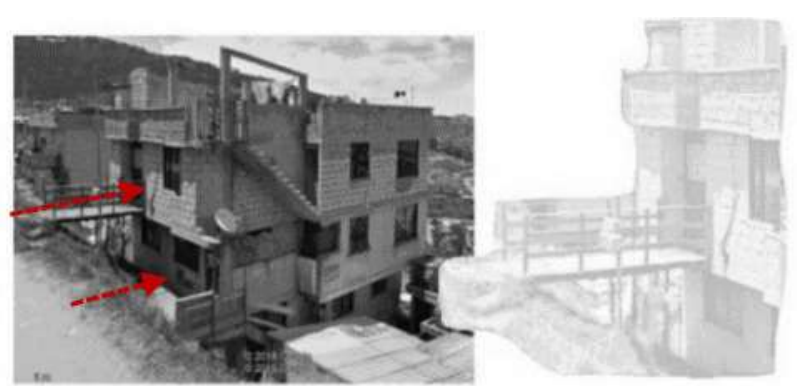

$1 X 10$ aDAPTADAS AL NIVEL DE CALLE

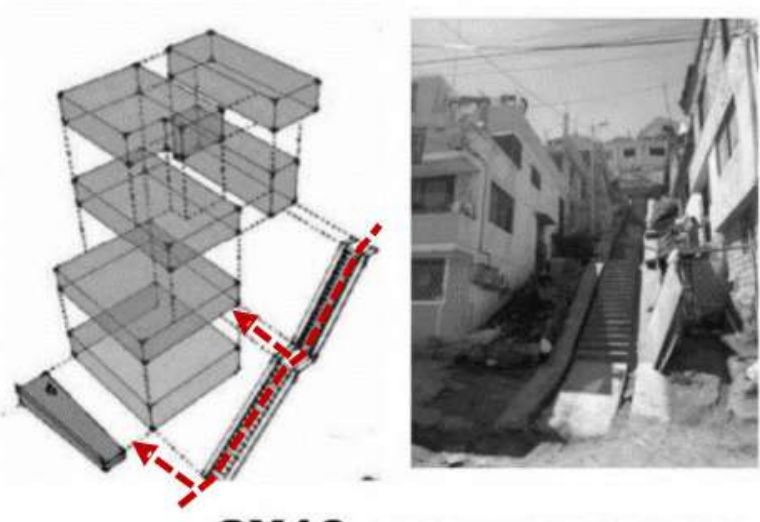

2X10 DEsde escalinata

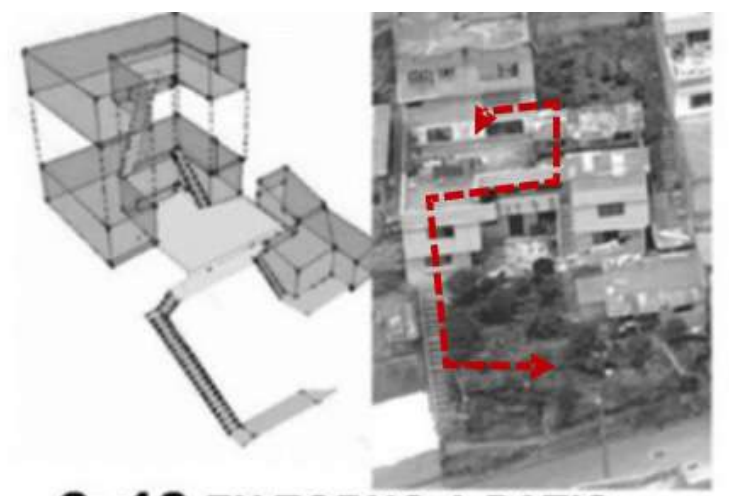

$6 \times 10$ EN TORNO A PATIO
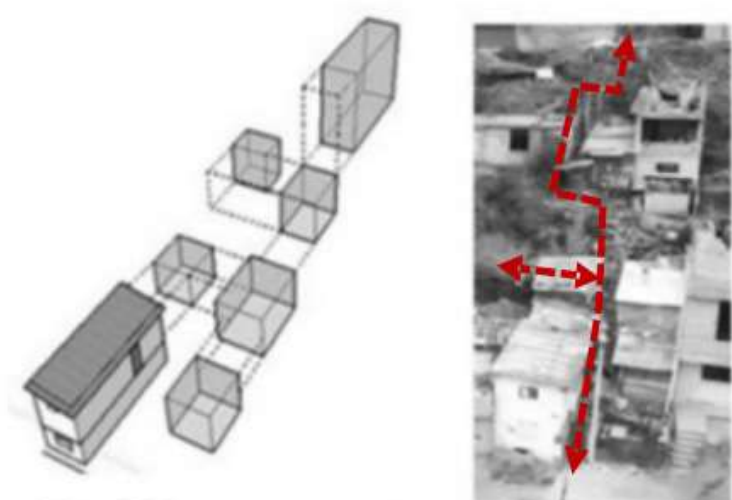

$7 \times 10$ SECUENCIAS HORIZONTALES

Figura 11. La escalera como elemento configurador (modelos abstractos). Fuente: Elaboración de la autora.

ilustra cómo la escalera básica lineal se acomoda en una pendiente de 26\%. Una primera adaptación intuitiva de la misma radica en suspender el descanso, con lo que la pendiente resulta de 31 grados; la siguiente modificación intuitiva identificada consiste en la transformación de la escalera en una escalinata en L, para obtener una pendiente de 41 grados; con el giro de la escalera de doble tramo horizontal se salva una pendiente de 52 grados; $y$, finalmente, el giro de 90 grados de la escalera lineal cubre una pendiente de $65^{\circ}$. Estos sistemas se combinan entre sí, generando también secuencias de rampas y gradas, o bien, se establecen en la escalera concentrada y el crecimiento vertical que se da en zonas relativamente planas.

Cabe destacar que, en las zonas con mayor pendiente (Tablas 1a e 1b), se origina asimismo una mayor diversidad de soluciones espaciales, y resoluciones ingeniosas para el problema de adaptación de la grada; razón por la cual se plantea aquí que, si bien la grada es un sistema altamente complejo, el desarrollo de la vivienda en pendiente es una posibilidad espacial y un reto para el diseño. De semejante manera, se observa que las moradas que se enfrentan a laderas tienen, en un 62\% de los casos, mejores condiciones de iluminación y de vista, como también de uso para terrazas, miradores y patios.

Modelos Abstractos: La escalera como elemento configurador En síntesis, podemos afirmar que las escaleras en la vivienda actúan como columna vertebral en la relación y funcionalidad de 


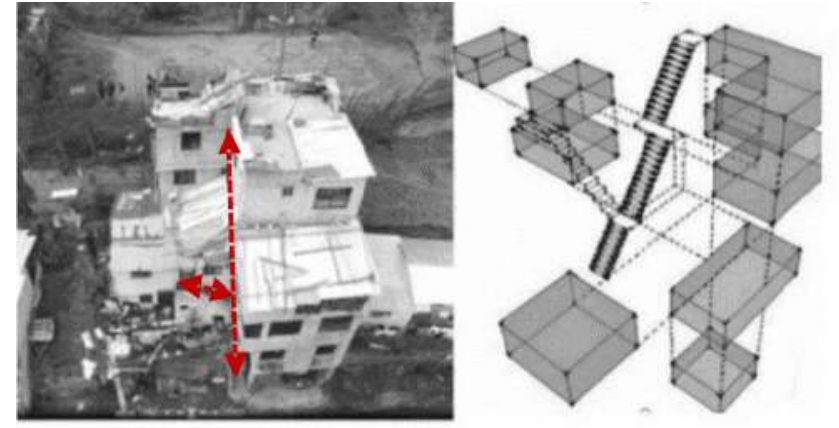

3x10 ESCALERA LINEAL CENTRAL

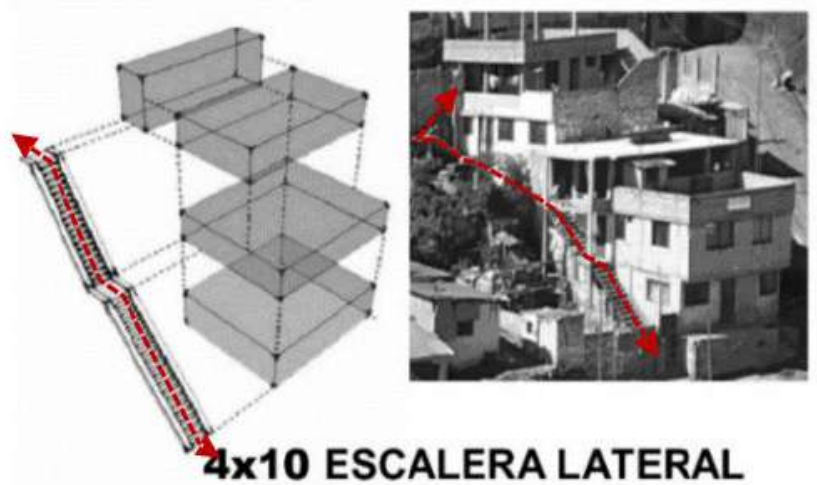

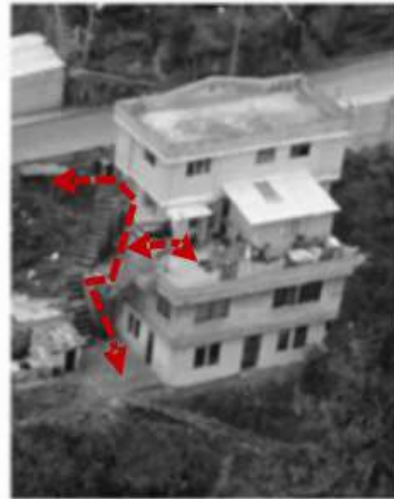

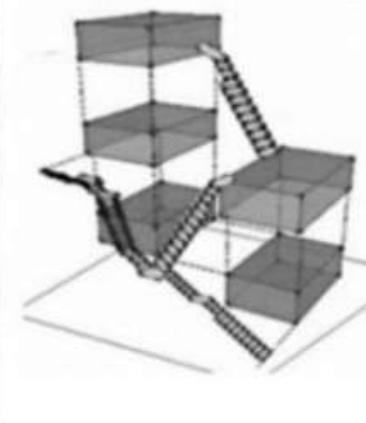

\section{$8 \times 10$ SECUENCIAS COMPLEJAS}

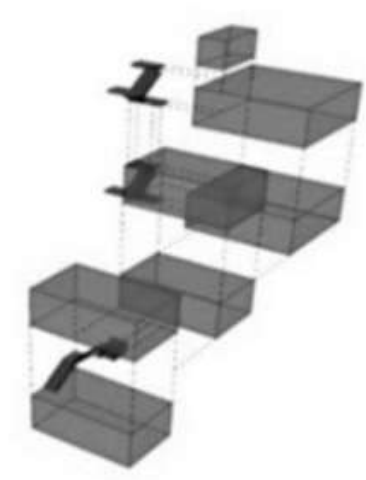

9x10 ESCALERA ENTRE-TERRAZAS

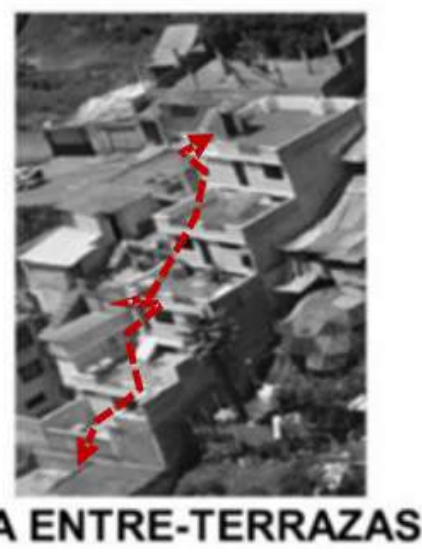

los elementos. En base a lo anterior, la escalera define los ritmos de crecimiento, tanto verticales como horizontales, marcando el acceso a cada una de las viviendas y, en conjunción con corredores y galerías, se define el sistema de relaciones espaciales, interiores y las relaciones con el entorno inmediato. A partir de todos los aspectos mencionados, se ha identificado las siguientes 10 (diez) maneras de subir, en las que se inscriben los 100 (cien) casos de estudio analizados:

\section{Adaptadas al nivel de Calle}

La casa se desarrolla en niveles con relación directa a la calle de acceso, y adaptándose a la pendiente natural de la misma. Este sistema funciona en pendientes de hasta 15 grados, las cuales permiten dos niveles de acceso a la vivienda.

\section{Organizadas desde escalinata comunal}

Cuando la pendiente de calle sobrepasa los 15 grados, la vía se convierte en una escalinata, las viviendas colindantes se acomodan directamente a la escalera y los descansos que se convierten en los espacios de acceso a la vivienda.

III. Lineal interior (columna vertebral)

En lotes que no tienen acceso directo a una vía lateral, la escalera se estructura al interior de la vivienda. El descanso se utiliza como elemento de acceso a la nueva vivienda, convirtiéndose la escalinata en la columna vertebral del edificio. 


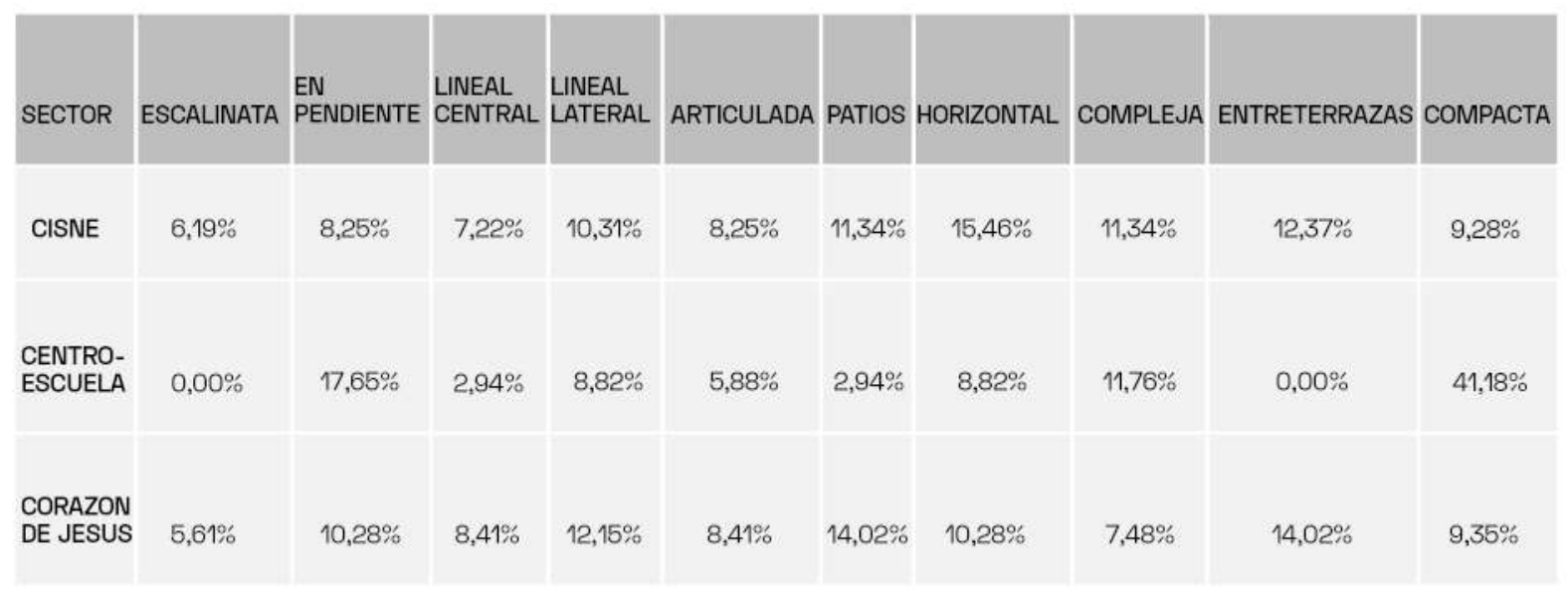

Tabla 1a. Tipos de escaleras por zonas. Fuente: Elaborado por la autora.

IV. Lineal interior lateral

La diferencia con el modelo anterior es que la grada se encuentra en el extremo lateral de la edificación.

V. Grada articuladora

En este caso, la escalera actúa como una bisagra o pivote que articula el crecimiento espacial, facilitando cambios de dirección en la distribución de los espacios, tanto horizontal como vertical.

VI. En torno al patio

Cuando es necesario la incorporación de un patio central, la escalera se distribuye vinculándose a este, de modo que define sus relaciones y dimensiones.

VII. Secuencias horizontales

Las secuencias que aparecen apegadas directamente a la topografía del lugar son: en espiral, lineales y en zigzag.

VIII. Secuencias complejas

Surgen de la combinación de los sistemas analizados anteriormente, y para adaptarse a la pendiente específica del lugar, se combinan rampas con desarrollos multidireccionales de la escalera, aprovechando tanto la pendiente natural de la calle como las escalinatas comunales.

IX. Entre terrazas

Combinando los distintos sistemas de colocación de las escaleras, se generan diversos sistemas de aterrazamiento. 


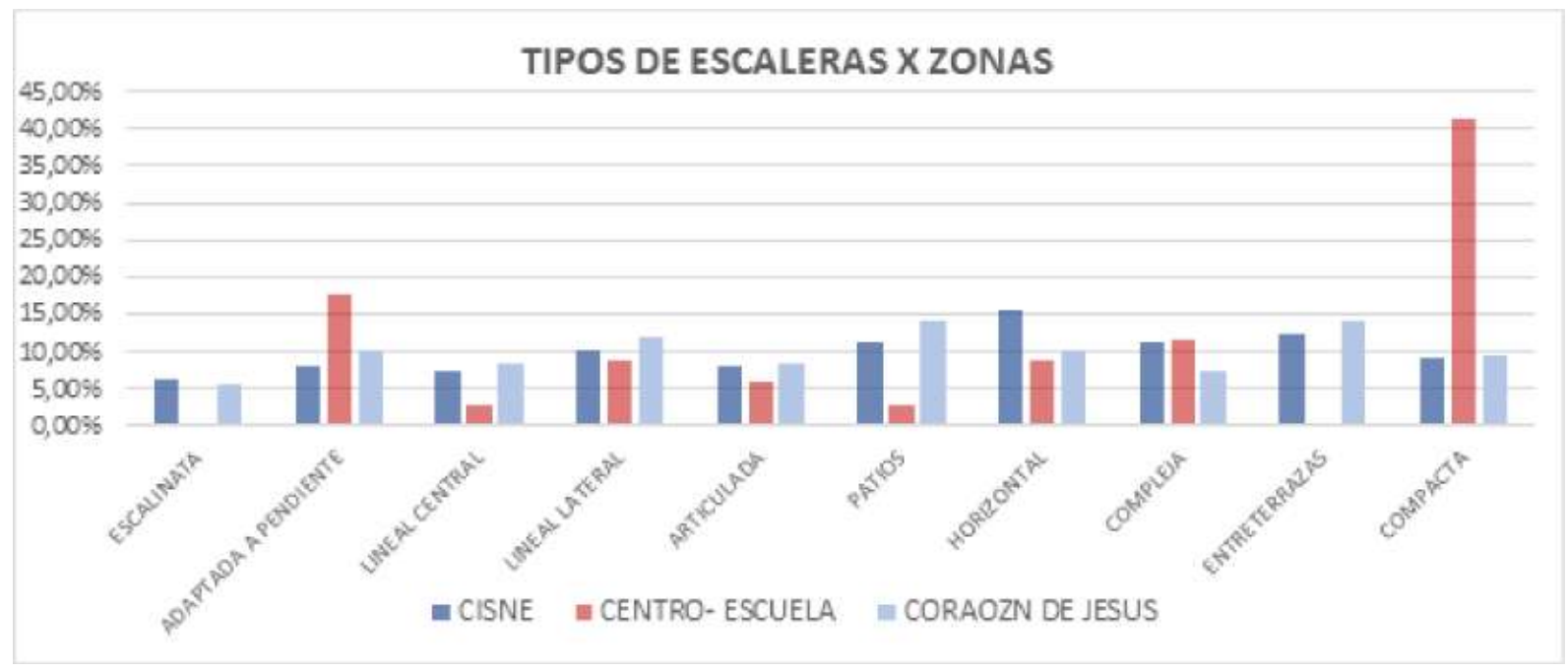

Tabla 1b. Tipos de escaleras por zonas. Fuente: Elaborado por la autora.

\section{Concentradas}

Se disponen escaleras en dos tramos, por lo general, en zonas de muy alta pendiente o, en caso de pendiente nula, el crecimiento se compacta en forma vertical.

\section{Discusión}

Gracias a las posibilidades técnicas que brinda el hormigón, Le Corbusier define la propuesta de La Citrohan, con la intención de generar en el diseño de la casa un sistema aprehensible y replicable; el desarrollo lineal de esta escalera genera también un esquema de organización funcional por niveles sencillo. Luego del análisis llevado a cabo, llama la atención haber encontrado en varias de las casas informales modelos de vivienda organizados desde una escalera lineal lateral y construidos intuitivamente, lo que recuerda a la sucesión de forjados presente en los proyectos de Le Corbusier. En otras palabras, gracias a las bondades técnicas que brinda el hormigón, el aporte teórico de Le Corbusier entra en estrecha relación con el pensamiento intuitivo pragmático de la autoconstrucción.

Otra posibilidad que brinda el sistema de hormigón armado, por el desarrollo de una estructura exenta de los muros, es el surgimiento de un tipo de construcción que denominamos casas patio, las mismas que en la vivienda informal permiten que a través del desarrollo de la escalera y sus secuencias la casa se configure y defina en torno a un patio central; esta solución permite, como en el caso de la promenade de La Saboye, que a través de la circulación se 

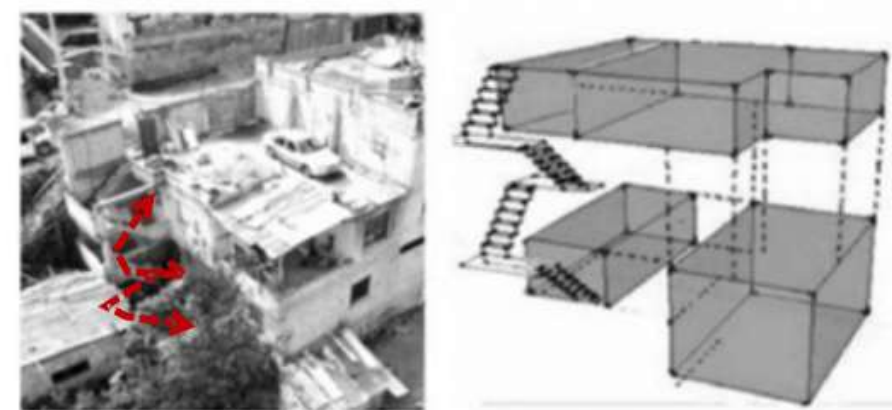

$10 \times 10$ ESCALERA CONCENTRADA

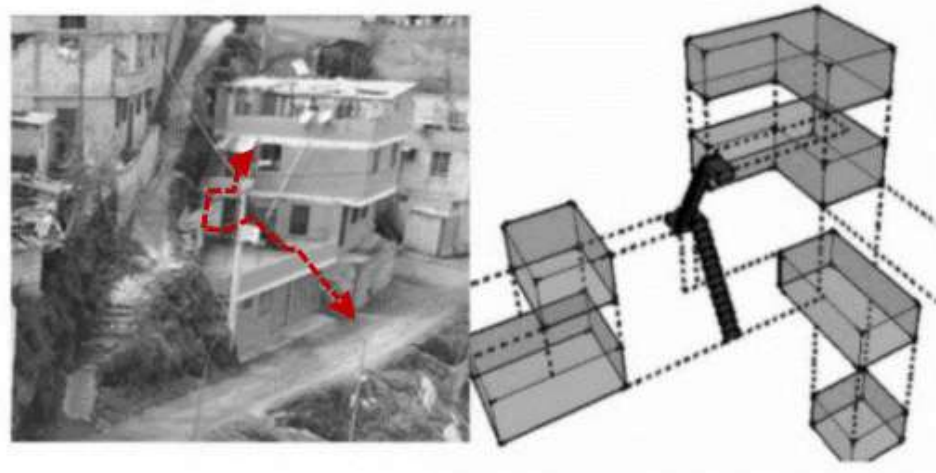

5x10 ESCALERA ARTICULADORA

Figura 12. La escalera como elemento configurador (modelos abstractos). Fuente: Elaboración de la autora.

realice un recorrido escénico, orientado al patio y a la espectacular vista que caracteriza las laderas montañosas de los barrios informales de Quito.

Si se comparan los tres esquemas de relación urbana, las propuestas de Le Corbusier, la de Maki y la de los barrios informales (Figura 10), salta a la vista que en el esquema de la calle de los 2 últimos esta se constituye en un vínculo del sistema que, sumado a la incorporación de espacios de mediación -como plazas, porches, galerías-, adquiere una gran dinamia, favoreciendo las conexiones a escala peatonales, estrechando las relaciones y vínculos a nivel de barrio y configurando así a la ciudad como un elemento fractal en el que es inseparable lo urbano de lo arquitectónico.

\section{Conclusiones}

A partir de la práctica llevada a cabo cabe destacar, en primer lugar, que las nuevas nociones espaciales y las posibilidades dinámicas de relación que se han incorporados al diseño a través de la promenade, constituyen una riqueza espacial que permite una relación igualmente dinámica y fluida en la vivienda, la cual es una necesidad vital también en la vivienda social, pues, según se pudo evidenciar a través de este estudio, la gente ha introducido de manera intuitiva estos conceptos en los ejemplos señalados de la construcción informal, como son la casa patio y la escalera entre terrazas. 
En segundo lugar, vale apreciar la posibilidad de construcción de la escalera de la ciudad informal a través de tramos o secuencias que se van articulando según decisiones en el tiempo, convirtiendo asi a la escalera en un mecanismo de transformación, que ofrece amplias posibilidades de desarrollo del espacio, a diferencia de la escalera tradicional que se define integramente desde su inicio y que condiciona una forma univoca de relaciones espaciales. Dicho mecanismo iterativo de conformación de la escalera hace posible que la casa o la calle sean una respuesta a las condiciones del habitar y no al revés.

En tercer lugar, resalta la noción de "ciudad lenta" con la que Maki da respuesta al principal cuestionamiento que motiva este artículo: ¿cómo la casa y la ciudad logran convertirse en una huella de su habitante? Se plantea con ello un nuevo concepto del diseño arquitectónico en que este dejaría de ser un acto especulativo, para volverse una respuesta específica a una necesidad concreta. La única limitante para conseguir aquello sería que implica un diseño paulatino en el tiempo, en vez de un acto integral de planificación prospectiva, es decir, se requiere que el arquitecto se convierta en un actor cotidiano partícipe en el desarrollo del espacio.

Finalmente, en cuarto lugar, del análisis de modelos abstractos aqui expuestos, se revelan muchas maneras de configurar el espacio, de dotarlo de distintas dinámicas, de probar cómo la autoconstrucción no debe ser un sistema minusvalorado o despreciable en el desarrollo de la vivienda social, ya que proporciona múltiples y ricas posibilidades de combinación espacial alternativas a los limitados modelos de vivienda social que los arquitectos utilizamos en la actualidad, pues los estudios realizados en la vivienda informal arrojan y se conectan con los ideales más altos de la arquitectura y otorgan pautas valederas para conseguir una vivienda adaptable, flexible y con capacidad de crecer a la medida de sus propios usuarios. 


\section{Referencias bibliográficas}

Aravena, A. y lacobelli, A. (2012). Elemental: manual de vivienda incremental $y$ diseño participativo $=$ incremental housing and participatory design manual. Ostfildern: Hatje Cantz.

Benton, T. (1987). Le Corbusier y la Promenade Architecturale. Revista Arquitectura COAM, (264-265), 38-47. Recuperado de: http://www.coam.es/media/Default\%20Files/fundacion/biblioteca/ revista-arquitectura-100/1987-1990/docs/revista-articulos/ revista-arquitectura-1987-n264-265-pag38-47.pdf

Bolivar, T. (2011). Acercamiento a las más importantes manifestaciones en la obra de los auto productores anónimos. En F. Carrión (ed.), Desde adentro: Viviendo la construcción de las ciudades con su gente (pp. 109.155). Quito, Ecuador: OLACHI.

Borja, J.; Carrión, F. y Corti, M. (2017). Introducción: Ciudades resistentes, ciudades posibles. En Ciudades resistentes, ciudades posibles (pp. 17-58). Barcelona: Editorial UOC.

Bullaro, L. (2014). Moderno y tropical: La reinterpretación de los principios lecorbusianos en las primeras obras de Oscar Niemeyer. Dearq, (15), 38-53.

Fernández Per, A.; Ollero, A. S. y Mozas, J. (2013). 10 historias sobre vivienda colectiva: análisis gráfico de diez obras esenciales. A+T Architecture publishers.

Fernández-Casas, I. d. T. (2016). Transformaciones incrementales en la vivienda informal consolidada: El caso de Santa María de las Lomas, Guayaquil. Arquitecturas del Sur: Arquitectura y Transformación Social, 34 (49), 6-21.

Garcia, M. y Muñoz, M. J. (2014). La invención del mundo otra vez... movimiento Megaestructural en España, 1960-70. Zarch, (3), 54-70.

Gonzales Cubero, J. (1991). La «Promenade Architecturale» y la ciudad. Anales de La Arquitectura, (3), 89-102.

Granja, M. B. y Cuenca, M. E. (2017). La ciudad paso a paso: Métodos de interacción para la configuración de barrios informales desde sus propias lógicas Quito-Ecuador. Paper presentado en IX Seminario Internacional de Investigación en Urbanismo, Barcelona-Bogotá, Barcelona. Recuperado de http://hdl. handle.net/2117/108202

Henríquez, R. (1956). La arquitectura moderna y Le Corbusier. Universidad de México, (11), 1-11.

Juárez Chicote, A. y Rodríguez Ramírez, F. (2014). El espacio intermedio y los origenes del TEAM 10. Proyecto Progreso y Arquitectura: Arquitecturas en Común, (11), 52.

Klaufus, C. (2009). Construir la ciudad andina: Planificación y autoconstrucción en Riobamba y Cuenca. Quito, Ecuador: Abya-Yala.

Krier, L. (2013). La arquitectura de la comunidad: La modernidad tradicional y la ecología del urbanismo. Barcelona (sp): Reverté.

Le Corbusier (1984). Le Corbusier et Pierre Jeanneret: Oeuvre complète. Zúrich: Girsberger.

Le Corbusier (1999). Precisiones respecto a un estado actual de la arquitectura y del urbanismo. Barcelona: Apóstrofe.

López Guzmán, R. (2003). La arquitectura en Iberoamérica en el siglo XX. América espejo de Europa 1900-1915. En R. López Guzmán y G. Espinosa Spínola (eds.). Arquitectura en Iberoamérica y Filipinas (351-377). Granada: Universidad de 
Granada, Manuales de arte iberoamericano.

Maki, F. (1964). Investigations in Collective Form. Saint Louis: Washington University St. Louis.

Monteys, X. (2017). La calle y la casa: Urbanismo de interiores. Barcelona: Gustavo Gili.

Monteys Roig, X. y Fuertes Pérez, P. (2016). Le Corbusier. Streets, promenades, scenes and artefacts. Journal of Architecture and Urbanism, 40(2), 151-161.

O’Byrne, M. C. (2018). La importancia de estudiar el plan director de Le Corbusier para Bogotá. Dearq, (22), 194-203. Recuperado de: http://dearq.u Uniandes.edu.co

O’Byrne Orozco, M. C. y Daza, R. (2018). La obra arquitectónica de Le Corbusier una contribución excepcional al movimiento moderno. Bogotá: Unidandes.

Pozueta E. J.; Lamíquiz D. F. y Porto S. M. (2009). La ciudad paseable: Recomendaciones para la consideración de los peatones en el planeamiento, el diseño urbano y la arquitectura. Madrid: Cedex.

Qiu, X. (2013). Fumihiko Maki and his theory of collective form: A study on its practical and pedagogical implications. Washington University in St. Louis

Quintana Guerrero, I. (2014). Hijos de la rue de Sèvres: Panorama de los colaboradores latinoamericanos de Le Corbusier en París. Dearq, (15), 14-22.

Reyes, J. M. (ed.) (2014). Jazz vs. palladio JF. Madrid (sp): Mairea Libros. Rodríguez Ramírez, F. (2016). Una arquitectura de las relaciones. En F. Rodríguez Ramírez (ed.), Un entendimiento infraestructural del proyecto arquitectónico (pp. 24-92). Madrid (sp): Textos de arquitectura y diseño.

Sáez Giráldez, E.; Garcia Calderón, J. y Roch, F. (2010). La ciudad desde la casa: Ciudades espontáneas en Lima. Revista INVI, 25(70), 77-116.

Salingaros, N.; Brain, D.; Duany, A.; Mechaffy, M. y Philibert-Petit, E. (2006). Vivienda social en Latinoamérica: Una metodología para utilizar procesos de autoorganización. (N. Hernández Trans.). Paper presentado en Congreso Ibero-Americano de Vivienda Social en Brasil.

Tomillo Castillo, A. (2016). El tiempo como sustancia de la forma: Una aproximación al museo de arte romano de Mérida desde los presupuestos del vitalismo. Tesis doctoral. Universidad Politécnica de Madrid, España.

Turner, J. F. C. (2018). Autoconstrucción: por una autonomía del habitar: Escritos sobre vivienda urbanismo autogestión; y holismo. La Rioja, España: Pepitas de calabaza. 